\title{
KINEMATIC ANALYSIS OF SOIL DRILLING MECHANISM USED IN AFFORESTATION
}

Gabriel Constantin Bogdanof ${ }^{1}$, Victor Moise ${ }^{2}$, Alexandra Liana Visan ${ }^{1}$, Gabriela Valeria Ciobanu ${ }^{1}$

${ }^{1}$ National Institute of Research - Development for Machines and Installations Designed to Agriculture and Food Industry, Romania; ${ }^{2}$ Politehnica University of Bucharest, Romania

gbogdanof@gmail.com

\begin{abstract}
Usually, the planting seedlings for terrain reforestation require a lot of manual labour and high number of workers, in order to minimize these requirements it is necessary to use a mechanical system serviced by minimum two qualified workers to carry out the planting holes. In this way the soil drilling equipment can be used in horizontal ground and also on slope terrains (max. $\left.15^{\circ}\right)$. This mechanism had been designed with an innovative drilling orientation system, which has the possibility to execute vertical planting holes. The kinematic analysis of the soil drilling mechanism was made using dedicated numerical modelling methods and simulation using MATLAB software applied on a specific R-RRR mechanisms that can be used to accurately reproduce the functioning of the experimental model developed by INMA Bucharest.
\end{abstract}

Keywords: kinematic analysis, soil drilling mechanism, innovative afforestation technology, degraded land, sloping terrain.

\section{Introduction}

In the paper the kinematic analysis of the soil drilling equipment used for slope terrain afforestation is presented. This is a novelty element in the frame of the innovative afforestation slope terrain technology developed by INMA, see Fig. 1, which can realize vertical planting holes even on inclined degraded lands and in this way the seedling development period is decreased, it increases their grip and ensures high development uniformity of the planting material [1].

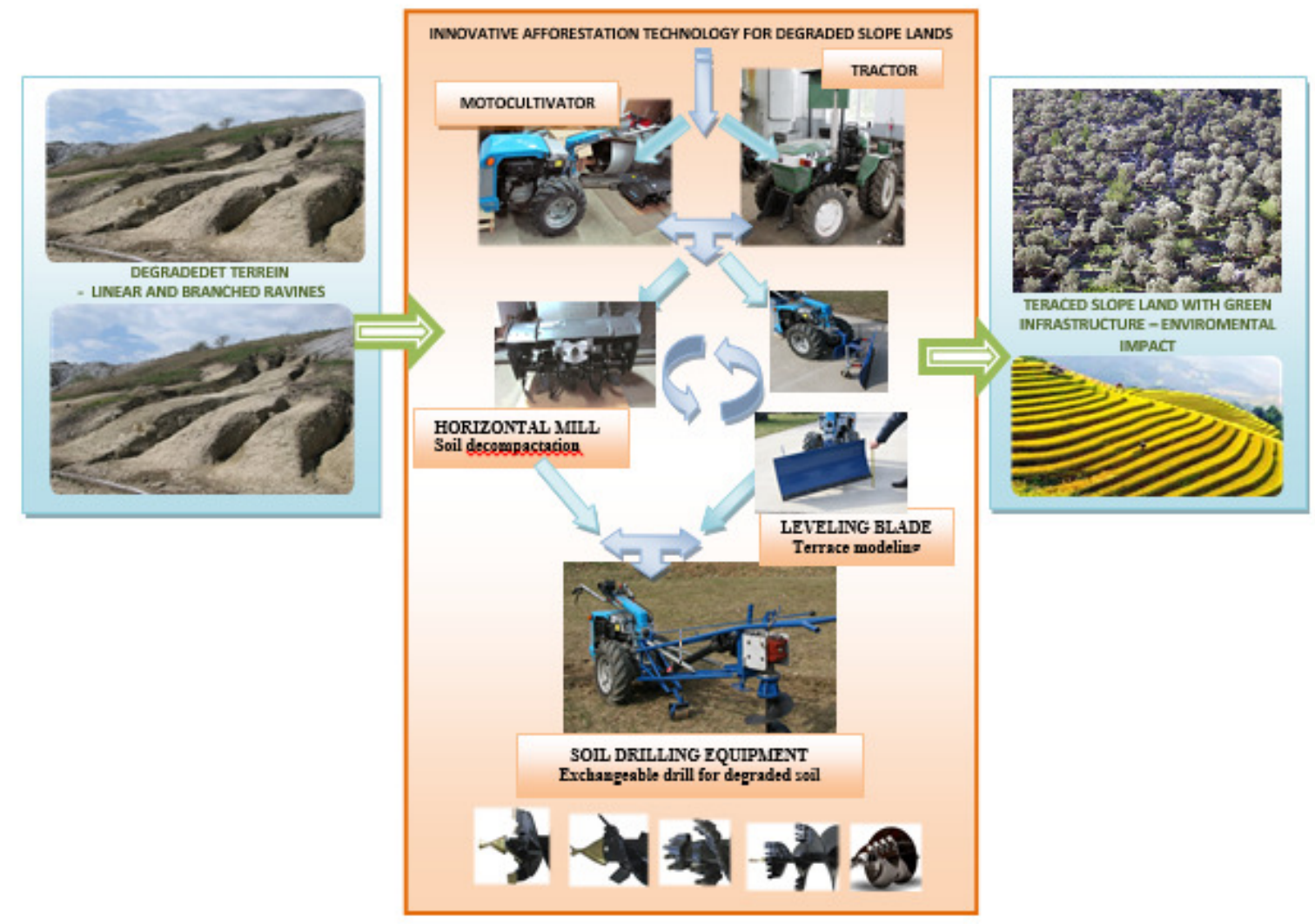

Fig. 1. Afforestation innovative technology

An advantage of this equipment is that it can be used in aggregates with high power motocultivators (19 HP) and low power tractors [2], power sources adequate in hard working conditions, (as degraded lands: water and wind eroded land, land displacement phenomena, land with excess water, salty land, degraded land and anthropogenic landfills, land stripped and artificial embankments) in order to conduct technological works safely and with stability. 
This technology was developed for maintenance and restoration of degraded areas especially on terraced slope terrains. In Romania, this innovative technology can be used on all territory (on hillside, riverside, on tableland, on planeside, etc.) where the terrain slope is not higher than $27 \%$ (approx. $15^{\circ}$ ) and even on mountainsides where they are executed terraces for soil stabilization.

In scientific literature, the degraded land planning works are usually carried out after modelling the terrain, respectively terracing. This infrastructure is usually carried out according to: the climatic area; soil degradation factors; soil physical-mechanical properties and type; soil deterioration grade and the type of the planting material, which must be chosen according to the native flora and fauna (important criteria by which the type of green infrastructure to be established is chosen) [3; 4]. From the functional and economic point of view the terracing infrastructure is the most efficient, especially for arid arias with stable land (calloused and fallow), because they have continuous or interrupted contour level lines. Execution of degraded land terracing is useful and such actions are usually performed from upstream to downstream, namely from the origin area to confluence with the main collector. Their width is between 0.5 and $1.5 \mathrm{~m}$ and they are placed at the distance of $1.5-3.0 \mathrm{~m}$ from their middle line. In this way can retain the rainfall and snowfall weather, and also can support the installed vegetation, from this point of view it is required that the terrace slope, namely the counterpoised angle is between $10-30^{\circ}$ [4-6]. This innovative technology is equipped with other two interchangeable equipments, soil mills - that loosen the soil and allow that nutrients to penetrate it and a levelling blade - that models the terrace surface and generates the counterpoised angle. The operation sequence can be easily adapted in accordance with the geo-climatic conditions of forested or rehabilitated areas and has a great impact from the socio-economic and environmental point of view, as:

- Development of innovative technical equipment in order to mechanize the technological process with approx. 40-50\% and to decrease the hand workforce required for the afforestation or reforestation process of the slope degraded lands;

- Encouraging degraded sloping landowners that are taken out of the forest to implement innovative technologies in order to rehabilitate them and to stop erosion and landslides

- Creating new jobs in forestry and green areas maintenance, especially for hilly with approx. $15 \%$;

- Slop degraded lands capitalization by planting valuable species of shrubs and trees, resistant to harsh climate conditions, with high regeneration capacity and pest resistance;

- Increasing Romanian material and technological resources to stop prevent and decrease slope soil degradation in accordance with the national regulations and the European ones.

The scientific literature from this field is very poor, but many experimental results are published on soil physical-mechanical properties [8] and many papers on mining drilling equipment.

\section{Materials and methods}

Next, the case is studied where the drilling equipment is carried and powered by a 19 HP motocultivator and equipped with a $300 \mathrm{~mm}$ auger diameter, the drilling depth and speed are adjusted by the operator in accordance to the soil type, if the soil is compacted, the drilling procedure is sequential or a dedicated auger is chosen, see Fig. 1 and 2.

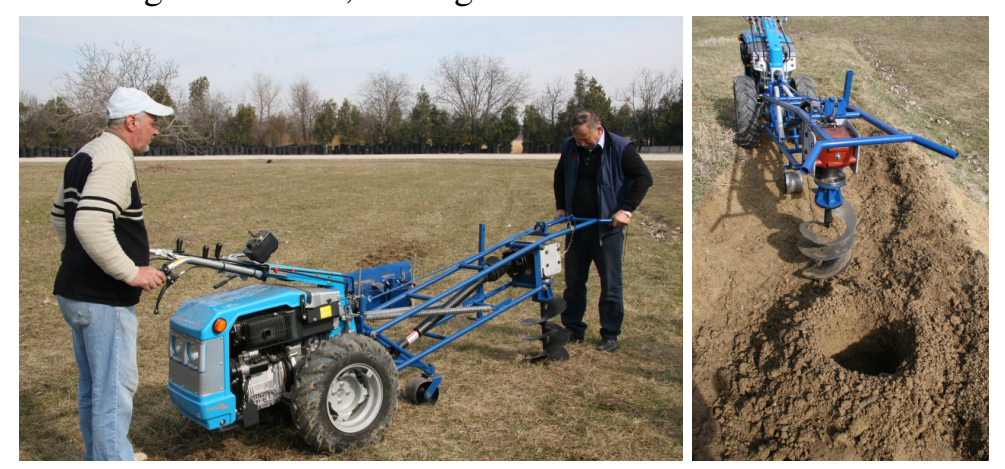

Fig. 2. Motocultivator - Soil drilling equipment BM - general view 
The equipment has its own wheelhouse to control the working parameters of the opening process, an auger guiding system that drills vertically planting holes, an auger position adjustment system adequate for slopes and a quick-release mounting drill system, see Fig. 2 [1;5].

From the theoretic point of view, the auger work position can have deviations from the initial position, and for this reason, in this paper the auger guiding mechanism is analysed from the kinematic point of view, without taking into consideration the operator influence on it.

The theoretic case study is focused on a quadrilateral mechanism, which corresponds in terms of construction with the above described equipment [6]. The $T_{i}$ point represents the auger driving point that is moving according to a vertical linear trajectory C.D. presented in Fig. 2.

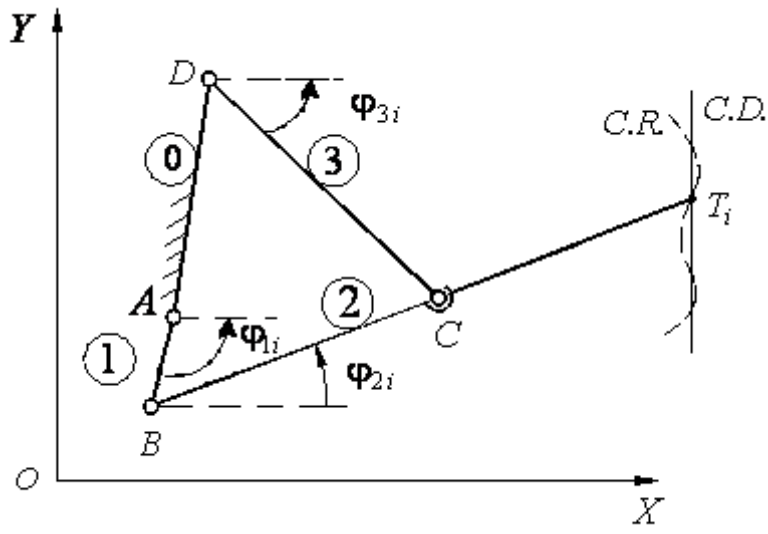

Fig. 2. Kinematic scheme of quadrilateral mechanism (that describes a vertical trajectory defined by points)

The kinematic analyses of the mathematical model was made using MATLAB numerical simulation program. The displacement of the tracer point $-T_{i}$, is made on a vertical linear trajectory initially C.D. and after that the real trajectory C.R. is estimated. Next the results of kinematic analyses will be presented using the mathematic algorithm and the working parameters, which define the quadrilateral mechanism evolution.

\section{Results and discussion}

The quadrilateral mechanism has 4 rotary articulations, and the mechanism is of R-RRR type. Taking into consideration the real model construction it is required to define the constraints in order to accurately simulate the auger trajectory (the active part of the soil drilling equipment) that defines the planting holes in correlation with the drilling depth, which is usually between 0.3 and $0.5 \mathrm{~m}$ (for young seedlings), but it can be bigger, if seedlings will be planted with the soil bale that can enter directly in fruit. Using the determination relation of the imposed maximum number of $T i$ and taking into account the mechanism structure 8 successive points are chosen to define the C.D. trajectory using an increment of 0.1 , see Table 1 .

Table 1

Tracer point coordinates $-T_{i}$

\begin{tabular}{|c|c|c|}
\hline No. & XT coordinate [m] & YT coordinate [m] \\
\hline 1 & 1.25 & 1.0 \\
\hline 2 & 1.25 & 0.9 \\
\hline 3 & 1.25 & 0.8 \\
\hline 4 & 1.25 & 0.7 \\
\hline 5 & 1.25 & 0.6 \\
\hline 6 & 1.25 & 0.5 \\
\hline 7 & 1.25 & 0.4 \\
\hline 8 & 1.25 & 0.3 \\
\hline
\end{tabular}


Projecting the segments on the Cartesian system abscissa and ordinate the vector equation (1) is determined needed for the mechanism mathematical modelling.

$$
\overline{O A}+\overline{A B}+\overline{B C}=\overline{O D}+\overline{D C}, \overline{O A}+\overline{A B}+\overline{B C}+\overline{C T_{i}}=\overline{O T_{i}},
$$

The equation system (2) is the result of the equations written on the contour $O A B C D O$ and $O A B T_{i} O$, where: $X A, Y A, X D, Y D, A B, B C, C D, B T$, are system unknowns; $\varphi_{1 i}, \varphi_{2 i}, \varphi_{3 i}$ the mechanism angles - variables, and $i=\overline{1,8}$ the increment of $T_{i}$.

$$
\left\{\begin{array}{l}
X A+A B \cos \varphi_{1 i}+B C \cos \varphi_{2 i}=X D+C D \cos \varphi_{3 i} \\
X A+A B \sin \varphi_{1 i}+B C \sin \varphi_{2 i}=X D+C D \sin \varphi_{3 i} \\
X A+A B \cos \varphi_{1 i}+B T \cos \varphi_{2 i}=X T_{i} \\
Y A+A B \sin \varphi_{1 i}+B T \sin \varphi_{2 i}=Y T_{i}, \\
i=\overline{1,8} .
\end{array}\right.
$$

Those equations were written in MATLAB algorithm and the results are presented in Table 2, where: $X A=X(1) ; Y A=X(2) ; A B=X(3) ; B C=X(4) ; C D=X(5) ; B T=X(6) ; X D=X(7) ; Y D=X(8)$, are element dimensions and the articulation position at the initial moment; the $X 9$ to $X 32$ are the values of $\varphi_{1 i}, \varphi_{2 i}, \varphi_{3 i}$ angles.

Table 2

\begin{tabular}{|c|c|c|c|}
\hline \multicolumn{2}{|c|}{ Coordinate of $x=f(i), \mathrm{m}$} & \multicolumn{2}{|c|}{ Angle $\varphi_{1 i}$, degrees } \\
\hline Initial & Final & Initial & Final \\
\hline$X(1)=0$ & $X(1)=0.09537$ & $X(9)=0.2$ & $X(9)=0.26274$ \\
\hline$X(2)=0$ & $X(2)=-0.09231$ & $X(10)=-0.15$ & $X(10)=-0.21704$ \\
\hline$X(3)=0.25$ & $X(3)=0.21677$ & $X(11)=-0.5$ & $X(11)=-0.57678$ \\
\hline$X(4)=0.7$ & $X(4)=0.77695$ & $X(12)=-0.85$ & $X(12)=-0.90215$ \\
\hline$X(5)=0.7$ & $X(5)=0.73445$ & $X(13)=-1.2$ & $X(13)=-1.21642$ \\
\hline$X(6)=1.4$ & $X(6)=1.40272$ & $X(14)=-1.55$ & $X(14)=-1.53144$ \\
\hline$X(7) 0$ & $X(7)=0.09598$ & $X(15)=-1.9$ & $X(15)=-1.85644$ \\
\hline$X(8)=0.5$ & $X(8)=0.49488$ & $X(16)=-2.24$ & $X(16)=-2.20324$ \\
\hline \multicolumn{2}{|c|}{ Angle $\varphi_{2 i}$, degrees } & \multicolumn{2}{|c|}{ Angle $\varphi_{3 i}$, degrees } \\
\hline Initial & Final & Initial & Final \\
\hline$X(17)=0.86$ & $X(17)=0.83096$ & $X(17)=0.86$ & $X(17)=0.83096$ \\
\hline$X(18)=0.86$ & $X(18)=0.83411$ & $X(18)=0.86$ & $X(18)=0.83411$ \\
\hline$X(19)=0.83$ & $X(19)=0.80438$ & $X(19)=0.83$ & $X(19)=0.80438$ \\
\hline$X(20)=0.78$ & $X(20)=0.75611$ & $X(20)=0.78$ & $X(20)=0.75611$ \\
\hline$X(21)=0.7$ & $X(21)=0.69252$ & $X(21)=0.7$ & $X(21)=0.69252$ \\
\hline$X(22)=0.65$ & $X(22)=0.61465$ & $X(22)=0.65$ & $X(22)=0.61465$ \\
\hline$X(23)=0.53$ & $X(23)=0.52272$ & $X(23)=0.53$ & $X(23)=0.52272$ \\
\hline$X(24)=0.4$ & $X(24)=0.41624$ & $X(24)=0.4$ & $X(24)=0.41624$ \\
\hline \\
\hline \multicolumn{4}{|c|}{$-2 A B\left[(X D-X A) \cos \varphi_{1 i}+(Y D-Y A) \sin \varphi_{1 i}\right]-$} \\
\hline \multicolumn{4}{|c|}{$-2 B C\left[(X D-X A) \cos \varphi_{2 i}+(Y D-Y A) \sin \varphi_{2 i}\right]+$} \\
\hline \multicolumn{4}{|c|}{$+2 A B \cdot B C \cos \left(\varphi_{1 i}-\varphi_{2 i}\right)=0$} \\
\hline \multicolumn{4}{|c|}{$X A+A B \cos \varphi_{1 i}+B T \cos \varphi_{2 i}=X T_{i}$} \\
\hline \multicolumn{4}{|c|}{$Y A+A B \sin \varphi_{1 i}+B T \sin \varphi_{2 i}=Y T_{i}$} \\
\hline \multicolumn{4}{|c|}{$i=\overline{1,9}$} \\
\hline
\end{tabular}

Mathematical model results

Taking into consideration that the $\varphi_{3 i}$ can be neglected, the equation system (2) is rewritten under the form (3) that has only 24 nonlinear equations with 27 variables. 
It was necessary to define the functions $f_{1 i}, f_{2 i}$ and $f_{3 i}$, in order to solve the nonlinear equation system as it is presented in relation (4), which was solved with the gradient method. For example, the $T_{i}$ coordinates are presented in Table 3 .

$$
\left\{\begin{aligned}
f_{1 i}= & A B^{2}+B C^{2}-C D^{2}+X A^{2}+Y A^{2}+X D^{2}+Y D^{2}-2(X A \cdot X D+Y A \cdot Y D)- \\
& -2 A B\left[(X D-X A) \cos \varphi_{1 i}+(Y D-Y A) \sin \varphi_{1 i}\right]- \\
& -2 B C\left[(X D-X A) \cos \varphi_{2 i}+(Y D-Y A) \sin \varphi_{2 i}\right]+ \\
& +2 A B \cdot B C \cos \left(\varphi_{1 i}-\varphi_{2 i}\right)=0 \\
f_{2 i}= & X A+A B \cos \varphi_{1 i}+B T \cos \varphi_{2 i}=X T_{i} \\
f_{3 i}= & Y A+A B \sin \varphi_{1 i}+B T \sin \varphi_{2 i}=Y T_{i} \\
i= & \overline{1,9}
\end{aligned}\right.
$$

\section{New $T_{i}$ coordinates}

Table 3

\begin{tabular}{|c|c|c|}
\hline No. & XT coordinates & YT coordinates \\
\hline 1 & 1.28 & 1.0 \\
\hline 2 & 1.28 & 0.9 \\
\hline 3 & 1.28 & 0.8 \\
\hline 4 & 1.28 & 0.7 \\
\hline 5 & 1.28 & 0.6 \\
\hline 6 & 1.28 & 0.5 \\
\hline 7 & 1.28 & 0.4 \\
\hline 8 & 1.28 & 0.3 \\
\hline
\end{tabular}

After running the mathematical program, in which the equations from system (4) were written, the results from Table 4 were obtained.

Mathematic model results and the working functional values

Table 4

\begin{tabular}{|c|c|c|c|c|c|}
\hline \multicolumn{2}{|c|}{ Coordinate $\boldsymbol{X}=\boldsymbol{f}(\boldsymbol{i}), \mathbf{m}$} & \multicolumn{2}{c|}{ Angle $\boldsymbol{\varphi}_{\mathbf{1 i}}$, degrees } & \multicolumn{2}{c|}{ Angle $\boldsymbol{\varphi}_{2 \boldsymbol{i}}$, degrees } \\
\hline Initial & Final & Initial & Final & Initial & Final \\
\hline$X(1)=0$ & $X(1)=0.14279$ & $X(9)=0.2$ & $X(9)=0.23841$ & $X(17)=0.93$ & $X(17)=0.85307$ \\
\hline$X(2)=0$ & $X(2)=-0.10700$ & $X(10)=-0.15$ & $X(10)=-0.22103$ & $X(18)=0.92$ & $X(18)=0.85493$ \\
\hline$X(3)=0.2$ & $X(3)=0.22345$ & $X(11)=-0.5$ & $X(11)=-0.57306$ & $X(19)=0.89$ & $X(19)=0.82512$ \\
\hline$X(4)=0.7$ & $X(4)=0.78854$ & $X(12)=-0.85$ & $X(12)=-0.89498$ & $X(20)=0.84$ & $X(20)=0.77704$ \\
\hline$X(5)=0.7$ & $X(5)=0.74408$ & $X(13)=-1.2$ & $X(13)=-1.20869$ & $X(21)=0.76$ & $X(21)=0.71346$ \\
\hline$X(6)=1.4$ & $X(6)=1.39954$ & $X(14)=-1.55$ & $X(14)=-1.52559$ & $X(22)=0.65$ & $X(22)=0.63502$ \\
\hline$X(7)=0$ & $X(7)=0.13594$ & $X(15)=-1.9$ & $X(15)=-1.85467$ & $X(23)=0.53$ & $X(23)=0.54160$ \\
\hline$X(8)=0.5$ & $X(8)=0.49689$ & $X(16)=-2.24$ & $X(16)=-2.20686$ & $X(24)=0.4$ & $X(24)=0.43264$ \\
\hline
\end{tabular}

The numeric results obtained have the following signification: $X 1$ to $X 8$, the position of rotary articulation $(X A=X(1) ; \quad Y A=X(2) ; \quad A B=X(3) ; \quad B C=X(4) ; \quad C D=X(5) ; \quad B T=X(6) ; \quad X D=X(7) ;$ $Y D=X(8)) ; X 9$ to $X 24$ the mechanism angles $\varphi_{1 i}$ and $\varphi_{2 i}$.

\section{Conclusions}

Analysing the mechanism kinematics and the results obtained from numeric analyses results in a vertical deviation of $1.0 \mathrm{~mm}$, which means a relative error of $0.08 \%$, and the absolute error of 0.001 . Thus, it can be stated that the mathematic model is chosen correctly and the quadrilateral mechanism, R-RRR type, can be successfully used for this equipment.

The quadrilateral mechanism modelled on PC and simulated on dedicated software, MATLAB, meets the technical-functional requirements and faithfully reproduces the experimental model behaviour that was developed by INMA Bucharest. 
The mathematical model constrains are adequately made and the drilling depth was properly chosen respecting the technical requirements of the planting operation that usually is between 0.3 and $0.5 \mathrm{~m}$ for young seedlings used in forestry in inaccessible tractor terrains. This parameter can be greater when this equipment is used to plant fruit orchards and support systems.

Now, plantations can be made when the fruit seedlings enter directly on bearing and for this the soil drilling equipment is necessary to make the holes deeper than $0.6 \mathrm{~m}$, in accordance with the fruit rooting system and the soil ballot, the case in which this mathematical model can also work.

This mathematic model can be used also to optimize the drilling equipment with high gauge in order to use new materials that can significantly reduce the weight and to increase the active stroke. The decisive role it has is the technologic development that starting with this model 3D virtual models can be designed to rapid prototyping experimental models to meet the technical and functional, requirements, and also operational and occupational safety for difficult working conditions (degraded land sloping, terraced, etc.).

\section{Acknowledgement}

The work has been funded by the Ministry of National Education and Research through the National Agency for Scientific Research, within the project entitled "Researches on substantiating an innovative technology for the afforestation of degraded slope lands", PN 16240104.

\section{References}

1. Bogdanof C. G., Vişan A. L., Păun A., Milea D. Sistem de reglare a poziţiei burghiului pentru executarea de locaşuri de plantare pe terenuri în pantă. OSIM patent application no. A00705 from 05.10.2016;

2. Vişan A.L., Bogdanof G.C., Milea D., Mircea C. Afforestation innovative technology of degraded slope lands in view of green infrastructure establishment, ISB INMA TEH 2016, pp. 481-488.

3. Vişan A.L., Bogdanof G.C., Milea D., Ciobanu G.V. "Researches on technologies for the afforestation of degraded slope lands", AGIR BULETIN 2016, pp. 62-67.

4. Vişan A.L., Bogdanof G.C., Milea D., Rural development and implementation of forestation technologies for sloping degraded terrains, Proceeding of 5th International Conference of Thermal Equipment, Renewable Energy and Rural Development, TE-RE-RD 2016, pp. 429-434.

5. Seceleanu I., “Amenajarea Padurilor", Ceres Publishing House, 2012;

6. Constandache C., Nistor S, "Reconstructia ecologica a terenurilor ravenate si alunecatoare din zona Subcarpatilor de curbura si a Podisului Moldovei", Silvica Publishing House, 2008;

7. Moise, V., Grecu, B., Voicu, Gh., Dugăeşescu I., Synthesis of the driving mechanism used to manufacture the machines for fruit tree digging pits. $37^{\text {th }}$ International Symposium Actual Tasks Agricultural Engineering, Opatijia, Croatia, 9-2 February 2009. pp. 519-526.

8. Prikner P., Kodesova Radka, Influence of pore size distribution on penetration resistance behaviour and dry density of clay-loam soil, Proceeding of 15th International Scientific Conference of Engineering for Rural Development 25-27.05.2016 Jelgava, Latvia, pp. 242-246. 